\title{
A Simple Accurate Formula for Calculating Saturation Vapor Pressure of Water and Ice
}

\author{
JIANHUA HUANG \\ College of Chemistry and Chemical Engineering, and College of Textile Science and Engineering, \\ Wuhan Textile University, Wuhan, Hubei, China
}

(Manuscript received 4 December 2017, in final form 22 February 2018)

\begin{abstract}
It is necessary to calculate the saturation vapor pressure of water and of ice for some purposes in many disciplines. A number of formulas are available for this calculation. These formulas either are tedious or are not very accurate. In this study, a new formula has been developed by integrating the Clausius-Clapeyron equation. This new formula is simple and easy to remember. In comparison with the International Association for the Properties of Water and Steam reference dataset, the mean relative errors from this new formula are only $0.001 \%$ and $0.006 \%$ for the saturation vapor pressure of water and of ice, respectively, within a wide range of temperatures from $-100^{\circ}$ to $100^{\circ} \mathrm{C}$. In addition, this new formula yields a mean relative error of $0.0005 \%$ within the commonly occurring temperature range $\left(10^{\circ}-40^{\circ} \mathrm{C}\right)$. Therefore, this new formula has significant advantages over the improved Magnus formula and can be used to calculate the saturation vapor pressure of water and of ice in a wide variety of disciplines.
\end{abstract}

\section{Introduction}

Atmospheric air consists of a number of gaseous components (e.g., nitrogen, oxygen, carbon dioxide, inert gas, and water vapor). Dry air exists when all water vapor has been removed from atmospheric air. The composition of dry air is relatively unvarying. Moist air is a mixture of dry air and water vapor. The amount of water vapor in moist air changes from zero to a maximum that relies on the temperature and pressure of atmospheric air. The latter condition is called saturation, a state of neutral equilibrium between moist air and the condensed water phase (ASHRAE 2013, chapter 8). The saturation water vapor pressure, which is a function of air temperature, provides a basis for determining other thermodynamic properties of moist air (humidity ratio, specific enthalpy, specific entropy, specific volume, etc.).

Goff and Gratch developed an accurate formula for calculating the saturation vapor pressure (Goff and Gratch 1945), and modified this formula later (Goff 1957). In 1966 the World Meteorological Organization (WMO) recommended its use, and the WMO meteorological tables were based on these formulas (Letestu 1966). Wexler and Hyland obtained new laboratory data on the saturation vapor pressure of water and derived

\footnotetext{
Corresponding author: Jianhua Huang, 2374513679@qq.com
}

another lengthy formula. Later, this formula and the computed values were incorporated in the ASHRAE Handbook-Fundamentals (Wexler 1976; Hyland and Wexler 1983; ASHRAE is derived from the American Society of Heating, Refrigerating, and Air-Conditioning Engineers). Wagner and Pruss developed a new formulation for the thermodynamic properties of ordinary water substance for general and scientific use, and later this formulation was adopted by the International Association for the Properties of Water and Steam (IAPWS) (Wagner and Pruss 1993, 2002; IAPWS 2016). In 2011, Wagner et al. developed a new equation, which has considerably less uncertainty, for calculating the saturation vapor pressure of ice (Wagner et al. 2011). The IAPWS adopted it soon thereafter (IAPWS 2011).

The values of saturation vapor pressure can be obtained by looking them up in the reference tables. When largescale computations are needed or temperatures with decimal points are reported, it is routine to calculate the saturation vapor pressure by using an accurate formula.

The Goff-Gratch, Hyland-Wexler, and Wagner-Pruss formulas are tedious and inconvenient for use in calculating the saturation vapor pressure. There has been much research on formulating the saturation vapor pressure. Bosen gave a formula for calculating the saturation vapor pressure of water with reasonable accuracy in the temperature range from $-51.1^{\circ}$ to $54.4^{\circ} \mathrm{C}$ (Bosen 1960). 
Langlois developed a fractional formula for computing the saturation vapor pressure of water and compared the results with the observed values in Byers (1959) and the formula in Berry et al. (1945). The percentage error vs the observations was found to be less than $0.5 \%$ over the temperature range of $0^{\circ}-35^{\circ} \mathrm{C}$ (Langlois 1967). Richards derived a four-degree polynomial for the saturation vapor pressure of water within the temperature range from $-50^{\circ}$ to $140^{\circ} \mathrm{C}$ (Richards 1971). Tabata suggested a quadratic formula that yielded the saturation vapor pressure with a mean percentage error of $0.17 \%$ within the temperature range from $0^{\circ}$ to $35^{\circ} \mathrm{C}$ (Tabata 1973). Lowe provided a sixth-degree polynomial formula for computing the saturation vapor pressure of water from $-50^{\circ}$ to $50^{\circ} \mathrm{C}$ and evaluated it against the Goff's equation. The results showed that the accuracy was very high (Lowe 1977). Rasmussen presented a five-degree polynomial and a sixth-degree polynomial for calculating the saturation vapor pressure over water (from $-50^{\circ}$ to $50^{\circ} \mathrm{C}$ ) and over ice (from $-50^{\circ}$ to $0^{\circ} \mathrm{C}$ ) and another four-degree polynomial for the saturation vapor pressure over ice. The maximum relative error was very low (Rasmussen 1978). Gueymard used a least squares method to obtain three formulas for the saturation vapor pressure over water and compared the computed results with the new ASHRAE reference data. It was shown that these three formulas could calculate the saturation vapor pressure with great accuracy (Gueymard 1993). Sanjari proposed a nonlinear equation for calculating the saturation vapor pressure of 75 pure substances by using multiple regression analysis, and comparison of the computed results and the data in the literature showed that the mean relative deviation was about $0.1 \%$ for water (Sanjari 2013). The temperature range was not given in Sanjari (2013).

The above-mentioned formulas are still complex. Some researchers made various attempts to establish simple equations fitted to the reference data by means of regression analysis. Tetens proposed two short formulas, one of which was of the Magnus form, for computing the saturation vapor pressure of water and of ice (Tetens 1930). The vapor pressure values given by this formula were acceptable for most meteorological purposes (Murray 1967), but the relative error provided by the Tetens formula increased with decreasing temperatures (Riegel 1974; Xu et al. 2012). In particular, at temperatures below $-25^{\circ} \mathrm{C}$ the errors were above 1\% (Murray 1967). Buck used a minimax fitting procedure over the temperature range of most interest in meteorology and derived two equations for calculating the saturation vapor pressure of water (from $-20^{\circ}$ to $50^{\circ} \mathrm{C}$ ) and of ice (from $-50^{\circ}$ to $0^{\circ} \mathrm{C}$ ), respectively (Buck 1981). Bolton introduced an empirical formula for the saturation vapor pressure of water and noted that the error was $0.4 \%$ over the temperature range from $-35^{\circ}$ to $35^{\circ} \mathrm{C}$ (Bolton 1980). Alduchov and Eskridge made a good use of an iterative process and least squares method to optimize the coefficients of the Magnus formula and recommended two equations for calculating the saturation vapor pressure over water (from $-40^{\circ}$ to $50^{\circ} \mathrm{C}$ ) and over ice (from $-80^{\circ}$ to $0^{\circ} \mathrm{C}$ ), respectively. These two equations yielded maximum relative error of less than $0.384 \%$ and $0.213 \%$, respectively (Alduchov and Eskridge 1996). Leckner calculated the saturation vapor pressure of water using a simple exponential function (Leckner 1978). Stephens estimated the saturation vapor pressure of water by using a simple formula that was based on the ClausiusClapeyron equation (Stephens 1990). Koutsoyiannis recently derived an equation for calculating saturation vapor pressure of water on the basis of the Clausius-Clapeyron equation and indicated that the relative difference from the reference datasets was small from $-40^{\circ}$ to $50^{\circ} \mathrm{C}$ (Koutsoyiannis 2012).

In nature, subzero temperatures occur in high-latitude cold regions. The temperatures in some areas have dropped to record levels because of a high frequency of cold weather (Turner et al. 2016). It has been predicted that about $20 \%$ of Earth's land surface will experience many heat waves by 2040 (Coumou and Robinson 2013). These changes will require a saturation vapor pressure formulation to be very accurate over a wide temperature range (from $-100^{\circ}$ to $100^{\circ} \mathrm{C}$ ).

For a vapor pressure formula, accuracy range is defined as the temperature range in which the relative error (RE) is less than $0.1 \%$ (Gueymard 1993). Although those formulas are simple, the computed results are not very accurate within a wide temperature range (from $-100^{\circ}$ to $100^{\circ} \mathrm{C}$ ). In addition, it is desirable to use a very accurate formula when extreme accuracy is required; for example, accurate calculation of rainfall, precise prediction of the rising surface temperature of Earth as a result of global warming, and accurate calculation of evapotranspiration in agriculture. None of those simple formulas is able to achieve this goal. The purpose of this study was to develop a simple and very accurate formulation for calculating the saturation vapor pressure of water and of ice. The computed results are extremely accurate for a wide temperature range from $-100^{\circ}$ to $100^{\circ} \mathrm{C}$.

\section{Methods}

\section{a. Currently existing equations}

There are four reference datasets for saturation vapor pressure in the literature. The IAPWS formulation was developed on the basis of experimental data that are of high quality and have been converted to the international temperature scale (ITS-90), and it is able to 
represent the experimental data to within the experimental uncertainty. Therefore, the IAPWS reference dataset was chosen in this study.

Wagner and Pruss proposed a complex equation for the saturation vapor pressure of water (Wagner and
Pruss 1993, 2002). Later this equation formed the basis of the IAPWS formulation. The differences between results from this formula and the results from the IAPWS formulation are extremely small. This formula is as follows:

$$
\begin{aligned}
\log _{e} \frac{P_{s}}{22064000}= & \frac{T_{c}}{T}\left[-7.85951783\left(1-\frac{T}{T_{c}}\right)+1.84408259\left(1-\frac{T}{T_{c}}\right)^{1.5}-11.7866497\left(1-\frac{T}{T_{c}}\right)^{3}\right. \\
& \left.+22.6807411\left(1-\frac{T}{T_{c}}\right)^{3.5}-15.9618719\left(1-\frac{T}{T_{c}}\right)^{4}+1.80122502\left(1-\frac{T}{T_{c}}\right)^{7.5}\right],
\end{aligned}
$$

where $P_{s}$ is the saturation water vapor pressure $(\mathrm{Pa}), T_{c}$ is the critical point temperature $(647.096 \mathrm{~K})$, and $T$ is the temperature $(\mathrm{K})$.

$$
\log _{e} \frac{P_{s}}{611.657}=\frac{T_{t}}{T}\left[21.2144006\left(\frac{T}{T_{t}}\right)^{0.00333333333}+27.3203819\left(\frac{T}{T_{t}}\right)^{1.20666667}+6.1059813\left(\frac{T}{T_{t}}\right)^{1.70333333}\right]
$$

where $T_{t}$ is the triple point temperature of water $(273.16 \mathrm{~K})$.

We here give the two most commonly used simple formulas for the saturation vapor pressure. The first is the improved Magnus formula with respect to water:

$$
P_{s}=610.94 e^{(17.625 t) /(t+243.04)} .
$$

The second is the improved Magnus formula with respect to ice:

$$
P_{s}=611.21 e^{(22.587 t) /(t+273.86)} .
$$

In both equations, $t$ is the temperature $\left({ }^{\circ} \mathrm{C}\right)$.

\section{b. Developing a new formulation}

In accordance with thermodynamic theory, the relationship between the saturation vapor pressure and the temperature at the equilibrium of two phases of water, because of entropy maximization, is governed by the Clausius-Clapeyron equation (Koutsoyiannis 2014; Ma et al. 2015):

$$
d P_{s} / d T=L /(T V),
$$

where $P_{s}$ is the saturation vapor pressure $(\mathrm{Pa}), T$ is the temperature of water or ice $(\mathrm{K}), L$ is the latent heat of vaporization $\left(\mathrm{J} \mathrm{kg}^{-1}\right)$, and $V$ is the specific volume of water vapor $\left(\mathrm{m}^{3} \mathrm{~kg}^{-1}\right)$. The specific volume of water vapor is determined by using the ideal gas law (Çengel and Boles 2011):
The equation for calculating the saturation vapor pressure of ice, developed by Wagner et al. (2011) and adopted by the IAPWS is given by

$$
V=R T / P_{s}
$$

where $R$ is the gas constant of water vapor (461.5 $\mathrm{J} \mathrm{kmol}^{-1} \mathrm{~K}^{-1}$ ). Submitting Eq. (6) into Eq. (5), after rearranging, gives

$$
d P / P=L d T /\left(R T^{2}\right) .
$$

The latent heat of vaporization of water is a linear function of the temperature (Henderson-Sellers 1984):

$$
L=m-n T,
$$

where $m$ is a coefficient equal to 3151378 and $n$ is a coefficient equal to 2386 . Substituting $L$ from Eq. (8) to Eq. (7) gives

$$
\frac{d P_{s}}{P_{s}}=\frac{(m-n T) d T}{R T^{2}}
$$

Integrating this equation yields

$$
\ln P_{s}=C-\frac{m}{R T}+\frac{n}{R} \ln T,
$$

where $C$ is the constant. To obtain this constant, suppose that the saturation vapor pressure of water is $P_{0}$ at a known temperature $T_{0}$. The step of putting $P_{0}$ and $T_{0}$ into Eq. (10) and solving it for $C$ yields

$$
C=\ln P_{0}+\frac{m}{R T_{0}}-\frac{n}{R} \ln T_{0} .
$$


TABLE 1. Saturation vapor pressure over the temperature range from $0^{\circ}$ to $100^{\circ} \mathrm{C}$ at an interval of $20^{\circ} \mathrm{C}$.

\begin{tabular}{|c|c|c|c|c|c|}
\hline \multirow[b]{2}{*}{ Temperature $\left({ }^{\circ} \mathrm{C}\right)$} & \multirow[b]{2}{*}{ Reference value $(\mathrm{Pa})$} & \multicolumn{2}{|c|}{ New formula } & \multicolumn{2}{|c|}{ Improved Magnus formula } \\
\hline & & $P_{s}(\mathrm{~Pa})$ & $\mathrm{RE}(\%)$ & $P_{s}(\mathrm{~Pa})$ & $\mathrm{RE}(\%)$ \\
\hline 0.01 & 611.655 & 611.689 & 0.0057 & 611.38 & 0.04 \\
\hline 20 & 2339.32 & 2339.32 & 0.0001 & 2333.44 & 0.25 \\
\hline 40 & 7384.94 & 7384.93 & 0.0001 & 7374.72 & 0.14 \\
\hline 60 & 19946.4 & 19946.1 & 0.0016 & 20023.0 & 0.38 \\
\hline 80 & 47414.5 & 47415.0 & 0.001 & 48039.7 & 1.32 \\
\hline 100 & 101418 & 101417 & 0.001 & 104077 & 2.62 \\
\hline
\end{tabular}

The next step of substituting Eq. (11) for $C$ in Eq. (10) and rewriting it gives

$$
P_{s}=\left(\frac{T_{0}}{T}\right)^{n / R} P_{0} \exp \left[\frac{m}{R T_{0}}\left(1-\frac{T_{0}}{T}\right)\right]
$$

Rewriting Eq. (12) yields

$$
P_{s}=\frac{\exp \left[\ln \left(P_{0} T_{0}^{n / R}\right)+\frac{m}{R T_{0}}-\frac{m / R}{T}\right]}{T^{n / R}} .
$$

In essence, this equation takes the following form:

$$
P_{s}=\frac{\exp \left(a-\frac{b}{T}\right)}{T^{c}},
$$

where $a, b$, and $c$ are the coefficients. After conversion of the unit of temperature to degrees Celsius, the above equation becomes

$$
P_{s}=\frac{\exp \left(a-\frac{b}{t+273.15}\right)}{(t+273.15)^{c}} .
$$

According to regression analysis, more regression coefficients bring more degrees of freedom and a more accurate fit of the regression equation to the data. If the constant term 273.15 in the denominator of Eq. (20) is viewed to be one regression coefficient, the RE is not adequately low. Therefore, the constant term 273.15 is considered to be two separate regression coefficients. It then follows that

$$
P_{s}=\frac{\exp \left(a-\frac{b}{t+d_{1}}\right)}{\left(t+d_{2}\right)^{c}}
$$

where $d_{1}$ and $d_{2}$ are coefficients.

\section{c. New formulas for saturation vapor pressure of water and ice}

The above equation was adopted to produce an accurate fit to the saturation vapor pressure of water in the IAPWS reference dataset. The five coefficients were obtained by using the least squares method, which minimizes the sum of the squared differences between the predicted values and the reference values. The regression equation originally carried as many decimal digits as the capability of the computer permitted. To achieve the least number of significant figures without an appreciable increase of the error, five coefficients have been truncated. The final formula for the saturation vapor pressure of water is given by

$$
P_{s}=\frac{\exp \left(34.494-\frac{4924.99}{t+237.1}\right)}{(t+105)^{1.57}} \quad\left(t>0^{\circ} \mathrm{C}\right) .
$$

\begin{tabular}{|c|c|c|c|c|c|}
\hline \multirow[b]{2}{*}{ Temperature $\left({ }^{\circ} \mathrm{C}\right)$} & \multirow[b]{2}{*}{ Reference value $(\mathrm{Pa})$} & \multicolumn{2}{|c|}{ New formula } & \multicolumn{2}{|c|}{ Improved Magnus formula } \\
\hline & & $P_{s}(\mathrm{~Pa})$ & $\mathrm{RE}(\%)$ & $P_{s}(\mathrm{~Pa})$ & $\operatorname{RE}(\%)$ \\
\hline-100 & 0.0014049 & 0.0014050 & 0.009 & 0.001393 & 0.819 \\
\hline-80 & 0.054773 & 0.05477 & 0.003 & 0.05472 & 0.095 \\
\hline-60 & 1.0813 & 1.0814 & 0.006 & 1.0817 & 0.028 \\
\hline-40 & 12.8412 & 12.841 & 0.004 & 12.834 & 0.055 \\
\hline-20 & 103.239 & 103.23 & 0.013 & 103.13 & 0.109 \\
\hline 0 & 611.153 & 611.29 & 0.023 & 611.21 & 0.009 \\
\hline
\end{tabular}

In a similar way, Eq. (16) was used to generate an accurate fit to the saturation vapor pressure of ice from the IAPWS reference values. There exist considerable

TABLE 2. Saturation vapor pressure over the temperature range from $-100^{\circ} \mathrm{C}$ to $0^{\circ} \mathrm{C}$ at an interval of $20^{\circ} \mathrm{C}$. 
TABLE 3. MAXRE, MRE, and accuracy range. Note that the MRE is calculated on the basis of 101 data points from $0^{\circ}$ to $100^{\circ} \mathrm{C}$, with an interval of $1^{\circ} \mathrm{C}$.

\begin{tabular}{lcc}
\hline \hline & Improved Magnus formula & New formula \\
\hline MAXRE (\%) & $2.62 \%$ at $100^{\circ} \mathrm{C}$ & $0.0057 \%$ at $0^{\circ} \mathrm{C}$ \\
MRE (\%) & $0.67 \%$ & $0.001 \%$ \\
Accuracy range & $0^{\circ}-3^{\circ} \mathrm{C} ; 43^{\circ}-53^{\circ} \mathrm{C}$ & $0^{\circ}-100^{\circ} \mathrm{C}$ \\
\hline
\end{tabular}

combinations of coefficients $d_{1}$ and $d_{2}$ that yield an RE of $0.004 \%-0.007 \%$. The following formula, which provides minimum significant digits with a small sacrifice in accuracy, was obtained for the saturation vapor pressure of ice:

$$
P_{s}=\frac{\exp \left(43.494-\frac{6545.8}{t+278}\right)}{(t+868)^{2}} \quad\left(t \leq 0^{\circ} \mathrm{C}\right) .
$$

\section{Results}

For comparisons, the saturation vapor pressure values of water from IAPWS were viewed to be the reference values. The saturation water vapor pressure values were calculated by Eq. (17) for temperatures ranging from $0^{\circ}$ to $100^{\circ} \mathrm{C}$ at an interval of $1^{\circ} \mathrm{C}$ and compared with the reference values. Table 1 lists the saturation water vapor pressure values from this new formula and the improved Magnus formula at an interval of $20^{\circ} \mathrm{C}$. The saturation water vapor pressures from Eq. (17) are almost identical to the reference values for this wide range of temperatures $\left(0^{\circ}-100^{\circ} \mathrm{C}\right)$.

The saturation vapor pressure values of ice were calculated by Eq. (18) for temperatures ranging from $-100^{\circ}$ to $0^{\circ} \mathrm{C}$ at an interval of $1^{\circ} \mathrm{C}$. As exhibited in Table 2 , the computed values from Eq. (18) are compared with the reference values. Again, the saturation vapor pressures of ice from Eq. (18) are very close to the reference values within a wide temperature range from $-100^{\circ}$ to $0^{\circ} \mathrm{C}$.

\section{Discussion}

It is critical to give the calculation error for a simple formula. To assess the accuracy of the new formula quantitatively, mean relative error (MRE; \%) and maximum relative error (MAXRE; \%) are selected as error criteria; they are respectively determined by

$$
\begin{aligned}
\text { MRE } & =\frac{1}{N} \sum_{i=1}^{N}\left|\frac{P_{s i}-P_{\mathrm{ss} i}}{P_{\mathrm{ss} i}}\right| \text { and } \\
\text { MAXRE } & =\max \sum_{i=1}^{N}\left|\frac{P_{s i}-P_{\mathrm{ss} i}}{P_{\mathrm{ss} i}}\right|,
\end{aligned}
$$

where $N$ is the number of data points, $P_{s i}$ is the calculated saturation vapor pressure $(\mathrm{Pa})$, and the $P_{\mathrm{ssi}}$ are the reference values $(\mathrm{Pa})$.

The MREs from Eq. (17) and the improved Magnus formula [Eq. (3)] are shown in Table 3. The MAXREs are also included, as well as the corresponding temperatures. The MRE of Eq. (17) is only $0.001 \%$, much lower than that of the improved Magnus formula. In other words, if the reference saturation vapor pressure is $100000 \mathrm{~Pa}$ at a given temperature, the absolute error resulting from Eq. (17) is $1 \mathrm{~Pa}$. Furthermore, this new formula yields an MRE of $0.0005 \%$ for the moderate thermal environment $\left(10^{\circ}-40^{\circ} \mathrm{C}\right)$. It is noteworthy that the MAXRE of Eq. (17) is $0.0057 \%$, lower than the

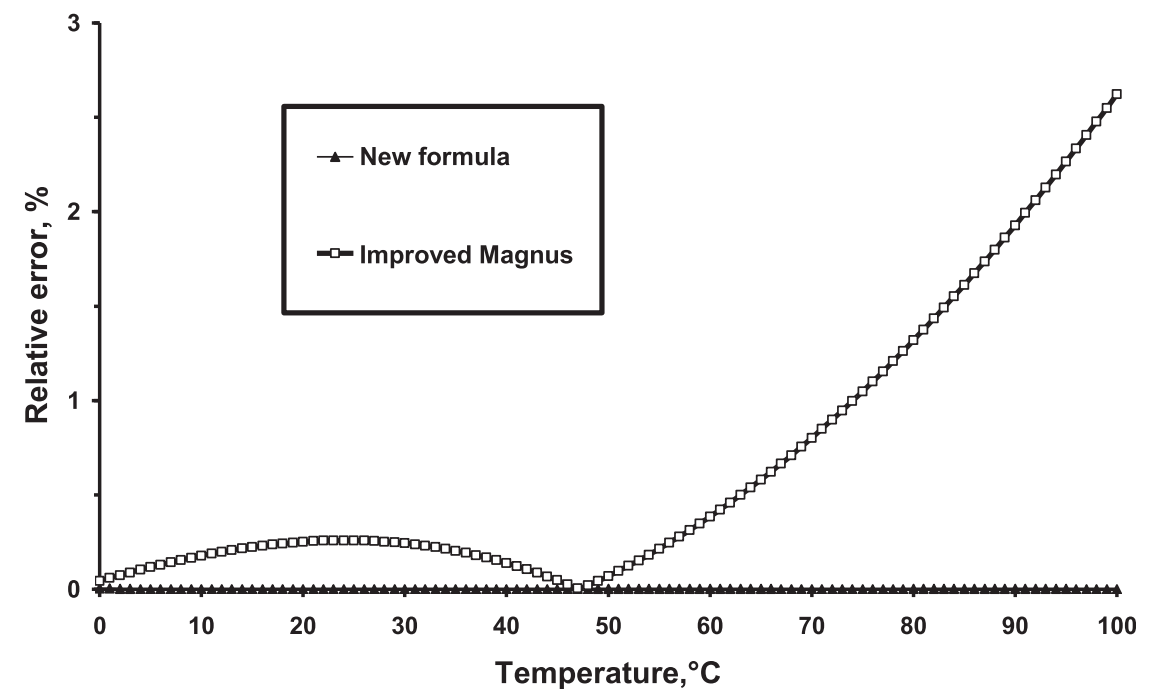

FIG. 1. Relative errors of saturation vapor pressure of water. 
TABLE 4. MAXRE, MRE, and accuracy range from four formulas. Note that the MRE is calculated on the basis of 101 data points from $-100^{\circ}$ to $0^{\circ} \mathrm{C}$, with an interval of $1^{\circ} \mathrm{C}$.

\begin{tabular}{lcc}
\hline \hline & Improved Magnus formula & New formula \\
\hline MAXRE (\%) & $0.819 \%$ at $-100^{\circ} \mathrm{C}$ & $0.023 \%$ at $0^{\circ} \mathrm{C}$ \\
MRE (\%) & $0.123 \%$ & $0.006 \%$ \\
Accuracy range & From $-80^{\circ}$ to $-29^{\circ} \mathrm{C}$; from $-14^{\circ}$ to $0^{\circ} \mathrm{C}$ & From $-100^{\circ}$ to $0{ }^{\circ} \mathrm{C}$ \\
\hline
\end{tabular}

MREs of the improved Magnus formula. Figure 1 shows a vivid picture of accuracy comparison. It appears as if the Eq. (17) line and the horizontal axis are indistinguishable from each other because of the extremely small MRE and MAXRE values. Therefore, the superiority of Eq. (17) over Eq. (3) can be readily identified from Tables 1 and 3 as well as Fig. 1.

As exhibited in Table 4, the MRE for saturation vapor pressure of ice from Eq. (18) is only $0.006 \%$, much lower than that of the improved Magnus formula. The MAXRE of Eq. (18) is $0.023 \%$. Again, the MAXRE from Eq. (18) is lower than the MRE of the improved Magnus formula. Thus, the superiority of Eq. (18) is vividly brought to light from Fig. 2.

As mentioned hereinbefore, the accuracy of those simple formulas is limited to narrow temperature ranges. The accuracy ranges for the new formula and the improved Magnus formula are displayed in Tables 2 and 4. The new Eqs. (17) and (18) are able to calculate the saturation vapor pressure very accurately over a wide range of temperatures. The improved Magnus formula yields $\mathrm{RE}$ exceeding $0.1 \%$ at temperatures above $53^{\circ} \mathrm{C}$.

In summary, this new formula is superior to the improved Magnus formula because of the following aspects:
1) It is much more accurate than the improved Magnus formula. The great accuracy can be ascribed to the fact that this new formula was derived from the Clausius-Clapeyron equation, which dictates the equilibrium between two phases of matter, and to the fact that more coefficients lead to a better fit to the reference dataset.

2) The great accuracy is valid throughout a wide temperature range from $-100^{\circ}$ to $100^{\circ} \mathrm{C}$.

3) It is simple and easy to remember, especially for the formula with respect to ice. If the same digit of a coefficient is counted one time, Eq. (18) has a total of 12 digits. Equations (17) and (18) share very similar coefficients (34.494 and 43.494).

Moist air does not, in strict terms, satisfy the ideal gas law. The saturation vapor pressure over water or ice should be multiplied by an enhancement factor to obtain the saturation vapor pressure for moist air. The enhancement factor, which is a weak function of temperature and pressure, is defined as the ratio of the saturation vapor pressure for moist air to that of pure water vapor over a plane of water (Buck 1981). The temperature effect is negligible. Thus, the enhancement factor is determined by (Alduchov and Eskridge 1996)

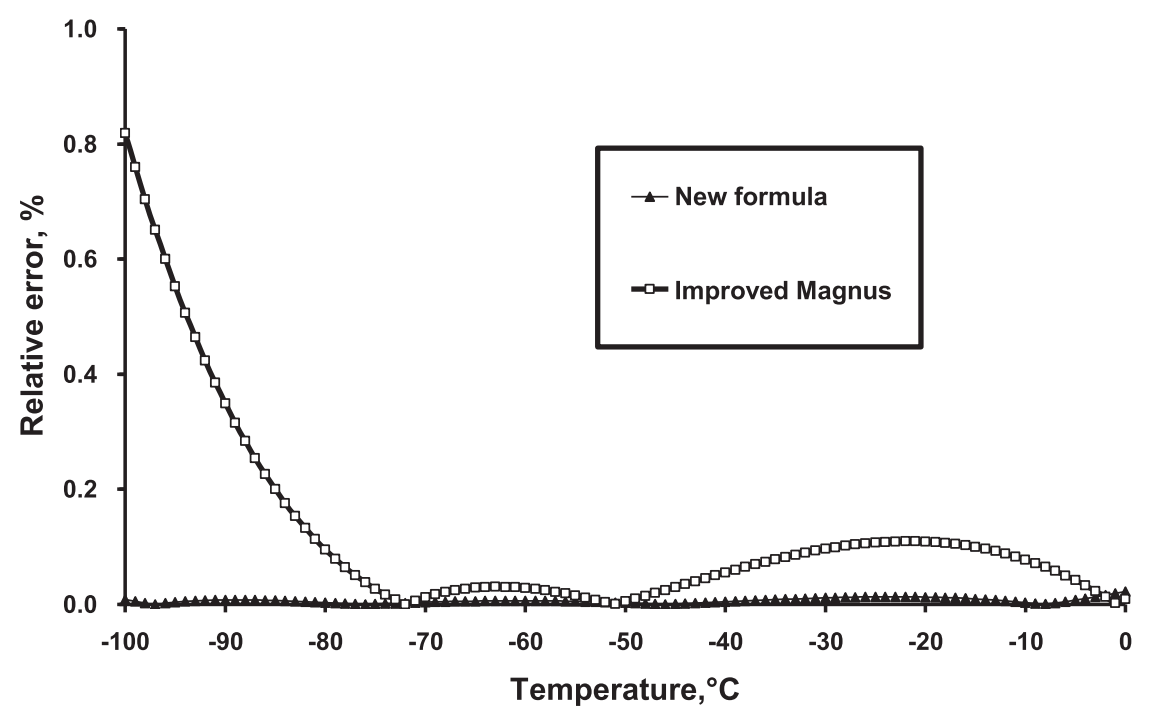

FIG. 2. Relative errors of saturation vapor pressure of ice. 


$$
\begin{aligned}
& f=1.00071 \exp (0.000000045 P) \quad \text { (with respect to water) and } \\
& f=0.99882 \exp (0.00000008 P) \quad \text { (with respect to ice), }
\end{aligned}
$$

where $f$ is the enhancement factor and $P$ is the atmospheric pressure $(\mathrm{Pa})$.

\section{Conclusions}

Computation of the saturation vapor pressure at a given temperature is frequently required for some applications in a wide variety of disciplines. There are a number of formulas available for this purpose. Some formulas are too complex and computationally inefficient. Few people use them. Others are not very accurate, either at low temperatures or at high temperatures. A new formula has been obtained, by integration of the Clausius-Clapeyron equation, for calculating the saturation vapor pressure. As compared with the reference data adopted by the IAPWS, this new formula yields mean relative errors of $0.001 \%$ and $0.006 \%$ for the saturation vapor pressure of water and of ice, respectively, within a wide range of temperatures from $-100^{\circ}$ to $100^{\circ} \mathrm{C}$, much lower than the MREs of the improved Magnus formula. Furthermore, the great accuracy of this formula is valid throughout the whole temperature range.

Because this new formula provides significant advantages over the improved Magnus formula in that it is simple and very accurate over a wide temperature range, it can be used to calculate the saturation vapor pressure for some applications in many disciplines. Despite the fact that the new formula has one more operation than the Magnus formula, it is desirable to select the new formula because of significant error reduction over a wide temperature range. Therefore, this new formula may be a feasible substitute for other simple and complex formulas because of its excellent performance.

Acknowledgments. This work was financially supported by the Hubei Key Laboratory for Digital Textile Technology.

\section{REFERENCES}

Alduchov, O. A., and R. E. Eskridge, 1996: Improved Magnus's form approximation of saturation vapor pressure. J. Appl. Meteor., 35, 601-609, https://doi.org/10.1175/1520-0450(1996) 035<0601:IMFAOS $>2.0$.CO;2.

ASHRAE, 2013: ASHRAE Handbook-Fundamentals. American Society of Heating, Refrigerating, and Air Conditioning Engineers, $1000 \mathrm{pp}$.

Berry, F. A., Jr., E. Bollay, and N. R. Beers, 1945: Handbook of Meteorology. McGraw-Hill, 343 pp.

Bolton, D., 1980: The computation of equivalent potential temperature. Mon. Wea. Rev., 108, 1046-1053, https://doi.org/ 10.1175/1520-0493(1980)108<1046:TCOEPT>2.0.CO;2.
Bosen, J. F., 1960: A formula for approximation of the saturation vapor pressure over water. Mon. Wea. Rev., 88, 275-276, https://doi.org/ 10.1175/1520-0493(1960)088<0275:AFFAOT >2.0.CO;2.

Buck, A. L., 1981: New equations for computing vapor pressure and enhancement factor. J. Appl. Meteor., 20, 1527-1532, https://doi. org/10.1175/1520-0450(1981)020<1527:NEFCVP>2.0.CO;2.

Byers, H. R., 1959: General Meteorology. McGraw-Hill, 158 pp.

Çengel, Y. A., and M. A. Boles, 2011: Thermodynamics: An Engineering Approach. McGraw-Hill, 978 pp.

Coumou, D., and A. Robinson, 2013: Historic and future increase in the global land area affected by monthly heat extremes. Environ. Res. Lett., 8, 034018, https:/doi.org/ 10.1088/1748-9326/8/3/034018.

Goff, J. A., 1957: Saturation pressure of water on the new kelvin scale. Amer. Soc. Heat. Vent. Eng. Trans., 63, 347-354.

- and S. Gratch, 1945: Thermodynamic properties of moist air. Amer. Soc. Heat. Vent. Eng. Trans., 51, 125-157.

Gueymard, C., 1993: Assessment of the accuracy and computing speed of simplified saturation vapor equations using a new reference dataset. J. Appl. Meteor., 32, 1294-1300, https://doi. org/10.1175/1520-0450(1993)032<1294:AOTAAC >2.0.CO;2.

Henderson-Sellers, B., 1984: A new formula for latent heat of vaporization of water as a function of temperature. Quart. J. Roy. Meteor. Soc., 110, 1186-1194, https://doi.org/10.1002/ qj. 49711046626.

Hyland, R. W., and A. Wexler, 1983: Formulations for the thermodynamic properties of the saturated phases of $\mathrm{H}_{2} \mathrm{O}$ from 173.15 K to 473.15 K. ASHRAE Trans., 89, 500-519.

IAPWS, 2011: Revised release on the pressure along the melting and sublimation curves of ordinary water substance. IAPWS Revised Release IAPWS R14-08(2011), 7 pp., http://www. iapws.org/relguide/MeltSub2011.pdf.

_ 2016: Revised release on the IAPWS formulation 1995 for the thermodynamic properties of ordinary water substance for general and scientific use. IAPWS Revised Release IAPWS R6-95 (2016), 19 pp., http://www.iapws.org/relguide/IAPWS95-2016.pdf.

Koutsoyiannis, D., 2012: Clausius-Clapeyron equation and saturation vapour pressure: Simple theory reconciled with practice. Eur. J. Phys., 33, 295-304, https://doi.org/10.1088/0143-0807/33/ 2/295.

, 2014: Entropy: From thermodynamics to hydrology. Entropy, 16, 1287-1314, https://doi.org/10.3390/e16031287.

Langlois, W. E., 1967: A rational approximation for saturation vapor pressure over the temperature range of sea water. J. Appl. Meteor., 6, 451, https://doi.org/10.1175/1520-0450 (1967)006<0451:ARAFSV > 2.0.CO;2.

Leckner, B., 1978: The spectral distribution of solar radiation at the earth's surface-Elements of a model. Sol. Energy, 20, 143150, https://doi.org/10.1016/0038-092X(78)90187-1.

Letestu, S., Ed., 1966: International meteorological tables. Tech. Doc. WMO 188, TP94, 327 pp., https://library.wmo.int/pmb_ ged/wmo_188e.pdf.

Lowe, P. R., 1977: An approximating polynomial for the computation of saturation water vapor. J. Appl. Meteor., 16, 100-103, https:// doi.org/10.1175/1520-0450(1977)016<0100:AAPFTC>2.0.CO;2.

Ma, W., L. Zhang, and C. Yang, 2015: Discussion of the applicability of the generalized Clausius-Clapeyron equation and the 
frozen fringe process. Earth Sci. Rev., 142, 47-59, https://doi. org/10.1016/j.earscirev.2015.01.003.

Murray, F. W., 1967: On the computation of saturation vapor pressure. J. Appl. Meteor., 6, 203-204, https://doi.org/10.1175/ 1520-0450(1967)006<0203:OTCOSV >2.0.CO;2.

Rasmussen, L. A., 1978: On the approximation of saturation vapor pressure. J. Appl. Meteor., 17, 1564-1565, https://doi.org/ 10.1175/1520-0450(1978)017<1564:OTAOSV > 2.0.CO;2.

Richards, J. M., 1971: A simple expression for the saturation vapor pressure of water in the range -50 to $140^{\circ} \mathrm{C}$. J. Phys., 4D, L15-L18, https://doi.org/10.1088/0022-3727/4/4/101.

Riegel, C. A., 1974: Comments on "A simple but accurate formula for the saturation vapor pressure over liquid water." J. Appl. Meteor., 13, 606-608, https://doi.org/10.1175/1520-0450(1974) $013<0606:$ COSBAF $>2.0 . \mathrm{CO} ; 2$.

Sanjari, E., 2013: A new simple method for accurate calculation of saturated vapor pressure. Thermochim. Acta, 560, 12-16, https://doi.org/10.1016/j.tca.2013.03.002.

Stephens, G. L., 1990: On the relationship between water vapor over the oceans and sea surface temperature. J. Climate, $\mathbf{3}$, 634-645, https://doi.org/10.1175/1520-0442(1990)003<0634: OTRBWV > 2.0.CO;2.

Tabata, S., 1973: A simple but accurate formula for the saturation vapor pressure over liquid water. J. Appl. Meteor., 12, 1410-1411, https:// doi.org/10.1175/1520-0450(1973)012<1410:ASBAFF>2.0.CO;2.

Tetens, O., 1930: Über einige meteorologische Begriffe (On some meteorological terms). Z. Geophys., 6, 297-309.
Turner, J., and Coauthors, 2016: Absence of 21st century warming on Antarctic Peninsula consistent with natural variability. Nature, 535, 411-415, https://doi.org/10.1038/ nature18645.

Wagner, W., and A. Pruss, 1993: International equations for the saturation properties of ordinary water substance. Revised according to the International Temperature Scale of 1990. Addendum to J. Phys. Chem. Ref. Data 16, 893 (1987). J. Phys. Chem. Ref. Data, 22, 783-787, https://doi.org/ 10.1063/1.555926.

— , and — 2002: The IAPWS formulation 1995 for the thermodynamic properties of ordinary water substance for general and scientific use. J. Phys. Chem. Ref. Data, 31, 387-535, https://doi.org/10.1063/1.1461829.

—, T. Riethmann, R. Feistel, and A. H. Harvey, 2011: New equations for the sublimation pressure and melting pressure of $\mathrm{H}_{2} \mathrm{O}$ ice Ih. J. Phys. Chem. Ref. Data, 40, 043103, https://doi. org/10.1063/1.3657937.

Wexler, A., 1976: Vapor pressure formulations for water in the range $0^{\circ} \mathrm{C}$ to $100^{\circ} \mathrm{C}$. A revision. J. Res. Natl. Bur. Stand., 80A, 775-785, https://nvlpubs.nist.gov/nistpubs/jres/80A/ jresv80An5-6p775_A1b.pdf.

Xu, J., Q. Wei, S. Peng, and Y. Yu, 2012: Error of saturation vapor pressure calculated by different formulas and its effect on calculation of reference evapotranspiration in high latitude cold region. Procedia Eng., 28, 43-48, https://doi.org/10.1016/ j.proeng.2012.01.680. 